DOI: 10.17805/zpu.2015.3.23

\title{
Влияние интернет-среды на личность и ее жизнедеятельность
}

\author{
Н. С. КОЗЛОВА \\ (ИВАНОВСКИЙ ГОСУДАРСТВЕННЫЙ УНИВЕРСИТЕТ)
}

В статье оценивается современное влияние Интернета на личность: позитивное и негативное. Сегодня наблюдается тенденция к формированию целой и многоаспектной области психологии, посвященной опосредуемому Интернетом поведению человека. В том числе становятся весьма актуальными и требующими эмпирических исследований вопросы о степени, полюсе и специфике воздействия виртуального мира на его пользователей. Число последних все время увеличивается, и среди них значительную долю составляют дети и подростки.

Основное внимание в данной работе сконцентрировано на оценке воздействия интернет-среды в целом, также анализируются последствия включенности личности в социальные сети. В исследовании, проведенном автором в 2013-2014 гг., приняли участие 153 человека (пользователей Интернета) в возрасте от 18 до 72 лет из Москвы, Санкт-Петербурга, Ярославля, Иваново и Ивановской области. Применены методы описательной статистики, корреляционный и факторный подходы.

Отмечается, что личность, использующая Интернет продуктивно как инструмент, характеризующаяся невысокой активностью в Сети, вообще не ощущает влияния Интернета. Те же, кто определяет для себя сильные, конкретные (позитивные или негативные) последствия приобщенности к виртуальной среде, обладают глубокой вовлеченностью в Интернет. При этом предполагается не конструктивное использование технических средств, а повышенное желание коммуникации, за счет которой реализуются виртуальная самопрезентация и стремление к публичности.

Пользователи, у которых вследствие приобщения к Интернету происходят какие-то личностные изменения или изменения в структуре жизнедеятельности, относятся к группе риска по формированию интернет-аддикции. В рамках изучения социально-психологических качеств подобных пользователей выявлено, что у таких лиц существуют проблемы в сфере реальной социальной идентичности, субъективного благополучия. Они также 
характеризуются разнообразием и силой эмоций. При изучении влияния социальных сетей обнаружены те же тенденции.

Сделан вывод, что именно социальное окружение человека становится той гранью, которая определяет его отношение и степень вовлеченность в виртуальный мир, а следовательно, и влияния, которое он окажет.

Ключевые слова: Интернет, социальные сети, интернет-аддикция, коммуникация, самопрезентация, публичность, социальная идентичность.

\section{ВВЕАЕНИЕ}

На сегодняшний день существует множество психологических исследований, целью которых является попытка определить влияние Интернета на личность, ее качества и жизнедеятельность. Общим в работах является то, что все авторы признают воздействие Сети как «виртуальной среды» намного глубже и глобальней, чем персонального компьютера и других технических систем.

Целью нашей работы является анализ как негативного, так и позитивного влияния Интернета на личность (влияние, которое субъективно ощущает сам пользователь), а также определение личностных особенностей, детерминирующих полюс воздействия виртуальной среды.

Мы попытаемся оценить общее воздействие Интернета на личность и ее жизнедеятельность без заранее выделенных сфер или аспектов. При этом мы исходим из того, что само по себе виртуальное пространство не способно изначально задать полюс своего влияния. По сути, Интернет является по отношению к личности индифферентным. Последствия зависят от социально-психологических особенностей лиц, вовлеченных в Сеть.

\section{ОБЗОР НАУЧНЫХ ИССАЕАОВАНИЙ ПО ТЕМЕ}

Большинство авторов сходится на том, что влияние Интернета на человеческую личность и ее деятельность нельзя оценить однозначно. К наиболее ранним российским работам в данной сфере, где высказывалась позиция о двойственном, дифференцированном воздействии Сети на личность, мотивационную сферу, относятся исследования А. Е. Войскунского, О. Н. Арестовой, А. Н. Бабанина (Арестова, Бабанин, Войскунский, 1996; 1999). В зарубежной психологии данная проблема представлена в трудах В. Фриндте, Т. Келера (Фриндте, Келер, 2000), М. А. Бэка с соавторами (Facebook profi les refl ..., 2010), А. Ажонсона (Joinson, 2003), Ш. Теркл (Turkle, 1995), а также С. А. Гослинга с коллегами (Manifestations of personality ..., 2011).

Бо́льшая часть психологических подходов, конечно, ориентирована на изучение негативных последствий вовлеченности человека в интернет-среду. Аостаточно часто встает вопрос о формировании интернет-аддикции, подмене реального общения виртуальным (как итог - появление термина «квазиобщение»), переносе потребностей. Однако помимо того, что Интернет всегда остается функциональным инструментом и в профессиональной сфере, и в плане разрешения конкретных проблем, он способен, на наш взгляд, быть позитивной составляющей развития или изменений личности. К данному выводу мы с коллегами пришли ранее. Так, виртуальное пространство может способствовать формированию виртуального коллективного субъекта, компенсирующего реальную структуру взаимодействия личности с людьми (Козлова, Сушков, 2014: Электронный ресурс).

В разных исследованиях авторы по-разному рассматривают возможности интернет-среды с точки зрения ее влияния на личность. Например, Н. В. Чудова, М. А. Ев- 
лампиева, Н. А. Рахимова писали в своих работах о зависимости образа «Я» и коммуникации человека от виртуального пространства (Чудова, Евлампиева, Рахимова, 2001: Электронный ресурс). Оценку Интернета как фактора, определяющего взаимодействие личности, мы встречаем в исследованиях И. В. Романова (Романов, 2005). В зарубежной психологии Р. Краут ставит вопрос об изменениях социальной интеграции под влиянием Сети (Internet paradox ..., 1998).

3десь основополагающим оказывается соединение системного подхода к социально-психологическим отношениям, представленного в работах В. Н. Мясищева (Мясищев, 2003) и И. Р. Сушкова (Сушков, 2008), со знаково-символической концепцией деятельности А. С. Выготского (Выготский, 1983: 96-97). При знаково-символическом опосредовании Интернетом личностная активность может формироваться в двух направлениях. В первом она превращается в деятельность, целью которой является преобразование материального мира. Во втором - реализуется в процессе общения, цель которого заключается в поддержании и развитии сообществ, а в конечном итоге в формировании коллективного субъекта (Сушков, 2008). Однако при наличии определенных проблем личности психологического порядка любая из этих тенденций может искажаться, в итоге появляется как чрезмерная деструктивная деятельность, так и непродуктивное общение, которые могут не способствовать развитию дичности.

\section{МЕТОАОАОГИЯ ИССАЕАОВАНИЯ}

В основной серии нашего исследования, проведенного в 2013-2014 гг., приняли участие 153 человека (пользователи Интернета) в возрасте от 18 до 72 лет. Респонденты являются жителями Москвы, Санкт-Петербурга, Ярославля, Иваново и Ивановской области. В качестве основных методов использовались тестирование и опрос. Авторская анкета содержала несколько блоков вопросов: на выявление основных форм активности в Сети, на реализацию в Сети базовых потребностей, способствующих формированию виртуального коллективного субъекта, на мотивационно-потребностную сферу пользователей, на оценку влияния Интернета самими пользователями.

В блок тестовых методик вошли:

1) шкала субъективного благополучия (Фетискин, Козлов, Мануйлов, 2002: $323-325)$;

2) исследование коммуникативных и организаторских склонностей (там же: 184-186);

3) диагностика мотива аффилиации (там же: 70-72);

4) опросник межличностных отношений (там же: 119-122);

5) тест-опросник оценки социально-коммуникативной компетентности (там же: 138-149);

6) оценка уровня общительности (Рогов, 1999: 52-55);

7) методика эмоциональной направленности личности (Аодонов, 2002);

8) методика оценки мотива власти (Ильин, 2002: 455);

9) опросник для выявления выраженности макиавеллизма (Ильин, 2009: 442-443);

10) методика «Кто Я?», расширенная вопросом «Кто Мы?» (Румянцева, 2006; Сушков, 1999).

Аополнительно в данной работе мы опираемся на результаты цикла наших исследований, проводимых на протяжении 2010-2013 гг., что позволило проследить динамику изменений характера деятельности и общения в социальных сетях. В совокупности выборка составила 378 человек (отдельная от указанной выборки данного иссле- 
дования) - пользователей Интернета в возрасте от 17 до 59 лет, из которых число женщин составило 214, мужчин - 164 (жители Костромы, Ярославля, Москвы, Санкт-Петербурга, Иванова и Ивановской области). Результаты проведенной работы опубликованы нами в 2014 г. (Козлова, 2014b). Заметим, что на одних этапах мы пытались охватить все социальные сети, представленные в России, на других анализировались конкретные: Fasebook, «ВКонтакте», «Одноклассники». Отдельно изучалась сеть Instagram (Козлова, 2014a).

При анализе результатов использовались методы описательной статистики, а также корреляционный и факторный анализ, сравнение независимых выборок при применении Т-критерия Стьюдента (см.: Граничина, 2012).

\section{РЕЗУАЬТАТЫ И ИХ ОБСУЖАЕНИЕ}

В первую очередь отметим, что сами пользователи сильнее ощущают позитивное влияние Интернета на них (средний балл 5 из 10 возможных) в отличие от негативного (средний балл 2,05 из 10). Это означает, что на сегодняшний день большинство людей либо действительно способны избегать возникновения проблем, вызванных приобщением к виртуальной культуре, либо не способны критично оценить последствия внедрения Интернета в их жизнь.

Аля того чтобы прояснить данный вопрос, остановимся на рассмотрении взаимосвязи полюса влияния со спецификой активности в Сети.

Те, кто склонен к высокой положительной оценке воздействия Интернета, в качестве конкретных позитивных последствий указывают следующее: увеличение числа тех, с кем они стали общаться ( $\mathrm{r}=0,31$, при $\mathrm{p} \leq 0,05)$; повышение собственной открытости для других $(\mathrm{r}=0,28$, при $\mathrm{p} \leq 0,05)$. Однако они отмечают, что стали меньше времени проводить на улице $(\mathrm{r}=0,35$, при $\mathrm{p} \leq 0,05)$, т. е. главная цель использования Интернета для них - это общение.

В Интернете они преимущественно общаются с теми, кого видят редко $(r=0,38$ при $\mathrm{p} \leq 0,01)$, и с теми, с кем взаимодействуют постоянно $(\mathrm{r}=0,43$ при $\mathrm{p} \leq 0,01)$. Они заводят новые знакомства $(r=0,31$ при $\mathrm{p} \leq 0,05)$, ищут единомышленников и вступают в группы по интересам $(\mathrm{r}=0,28$ при $\mathrm{p} \leq 0,05)$, становятся участниками форумов $(\mathrm{r}=0,29$ при $\mathrm{p} \leq 0,05)$ и различных опросов $(\mathrm{r}=0,33$ при $\mathrm{p} \leq 0,05)$.

Возникает вопрос: в чем главная цель виртуального общения для них?

Одним их самых важных моментов является то, что они именно в виртуальной среде реализуют базовые потребности: в уходе от одиночества $(\mathrm{r}=0,39$ при $\mathrm{p} \leq 0,01)$, в идентичности $(r=0,28$ при $\mathrm{p} \leq 0,05)$, в самопрезентации $(\mathrm{r}=0,29$ при $\mathrm{p} \leq 0,05)$, в публичности $(\mathrm{r}=0,32$ при $\mathrm{p} \leq 0,05)$.

Как мы уже писали, именно такой «набор» способствует возникновению виртуального коллективного субъекта: «...если личность стремится одновременно достичь идентичности с другими, создать новый образ Я, стать публичным лицом, и при этом у нее возникает ощущение, что она сможет избежать одиночества, то возникает ощущение становления частью активнодействующего сообщества, которое является значимым для нее. И так как все эти процессы легче и, главное, одновременно легче осуществляются в виртуальном мире, то можно предполагать, что виртуальный коллективный субъект, в силу своей большей доступности, может стать более актуальным Аля личности, чем реальный» (Сушков, Козлова, 2014: 58). Это подкрепляется тем, что такие пользователи отводят Интернету в целом ведущую роль в структуре своей жизнедеятельности $(\mathrm{r}=0,33$ при $\mathrm{p} \leq 0,05)$. 
Из всех изучаемых социально-психологических качеств, нами выявлены взаимосвязи только с эмоциональной направленностью и реальной идентичностью личности.

Следует подчеркнуть, что лица, позитивно оценивающие влияния Интернета, имеют сильную выраженность сразу нескольких типов направленности эмоций: практическая $(\mathrm{r}=0,30$ при $\mathrm{p} \leq 0,05)$, пугностическая ${ }^{1}(\mathrm{r}=0,35$ при $\mathrm{p} \leq 0,05)$, романтическая $(\mathrm{r}=0,30$ при $\mathrm{p} \leq 0,05)$ и гностическая $(\mathrm{r}=0,29$ при $\mathrm{p} \leq 0,05)$.

В отношении реальной социальной идентичности у них присутствуют серьезные проблемы. Они не относят себя ни к категории «мужчины/женщины» $(\mathrm{r}=-0,34$ при $\mathrm{p} \leq 0,05)$, ни «дети» $(\mathrm{r}=-0,35$ при $\mathrm{p} \leq 0,05)$, ни «члены семьи» $(\mathrm{r}=-0,31$ при $\mathrm{p} \leq 0,05)$. Это означает, что такие респонденты не обладают той идентичностью (гендерной и связанной с семейной сферой), которая характерна для личности, погруженной в реальный мир.

Таким образом, можно говорить, что положительная оценка Интернета и его последствий для личности связана со специфическими особенностями: ярко выраженными, сильными, разнообразными эмоциями и проблемами с реальной идентичностью. Такие пользователи оказываются очень сильно вовлеченными в Сеть. Речь идет в первую очередь об активности в сфере взаимодействия, поскольку никакими функциональными, связывающими их с физической реальностью, возможностями Интернета они не пользуются.

Кроме этого, реализация базовых потребностей переносится из реальности в виртуальность за счет возможности формирования виртуального коллективного субъекта.

На наш взгляд, такие люди представляют собой группу риска по формированию интернет-аддикции и ухода из реальности в виртуальный мир. И значит, что одним из критериев зависимости можно считать позитивную оценку личностью последствий Интернета (в данном случае она является не критичной и не конструктивной с точки зрения объективной реальности).

Если еще тоньше дифференцировать позитивные последствия, отмечаемые пользователями сетей, то обнаруживается наибольшая популярность следующих аспектов: общение, поддержание контакта с теми, кто находится далеко (отмечают $68 \%$ респондентов), расширение знаний о других (51\%), когнитивное развитие, расширение знаний о событиях в мире (53\%), эрудированность $(49 \%)$, развлечения $(61 \%)$. Меньше всего Интернет, по мнению испытуемых, помогает в дичной жизни. Подобные изменения отметили лишь около $8 \%$ респондентов.

Рассмотренной группе респондентов противопоставлено мнение людей, негативно оценивающих влияние Интернета. Они конкретизируют подобное влияние следующим образом: Интернет отвлекает их от решения реальных проблем $(\mathrm{r}=0,41$ при $\mathrm{p} \leq 0,01)$ и много времени просто уходит впустую $(\mathrm{r}=0,43$ при $\mathrm{p} \leq 0,01)$, возникают конфликты в семье $(\mathrm{r}=0,52$ при $\mathrm{p} \leq 0,01)$. Как и в предыдущем случае (при позитивной оценке интернет-влияния), такие пользователи не характеризуются познавательной активностью, информация о событиях и новости их не интересуют $(\mathrm{r}=-0,30$ при $\mathrm{p} \leq 0,05)$. Но самое главное, что у них вообще невозможно выделить никакого приоритетного направления деятельности, общения в виртуальном пространстве, которое было бы им характерно.

Притом что, по их мнению, Сеть много времени забирает напрасно, так как личные проблемы не решаются и появляются новые, совершенно не ясно, чем их привлекает Интернет. Можно предположить, что они занимаются всем понемногу, дибо они целенаправленно уходят от ответа, прибегая к сложившимся социальным стереотипам. 
Что же касается их социально-психологических особенностей, то им свойственна высокая напряженность $(\mathrm{r}=0,35$ при $\mathrm{p} \leq 0,05)$, как составляющая их переживания субъективного благополучия. Выявлено и отсутствие у них сформированной профессиональной идентичности ( $\mathrm{r}=-0,34$ при $\mathrm{p} \leq 0,05)$.

В результате можно предположить, что при наличии негативной оценки интернет-воздействия Сеть тем не менее может занимать большое пространство в жизнедеятельности личности. При этом сама активность в виртуальном мире не получает ярко выраженного направления. Такая тенденция может быть связана с нарушением ощущения благополучия, которое, видимо, затрагивает и социальную идентичность в профессиональном плане.

Стоит добавить, что именно «пустая трата времени» лидирует в перечне негативных последствий приобщения к Сети (так считает 47\% респондентов). Также популярны ответы «сидячий образ жизни» (35\%) и уменьшение «живого общения» $(29 \%)$. Реже всего виртуальная среда приводит, с точки зрения пользователей, к ухудшению коммуникативных навыков (4\%).

Аля более глубокого анализа интернет-воздействия мы провели факторный анализ. Результаты представлены в таблице.

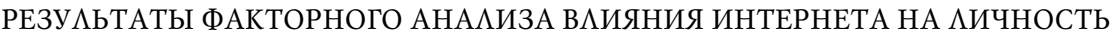

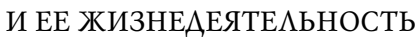 \\ OUTCOMES OF THE FACTOR ANALYSIS OF INFLUENCE OF THE INTERNET ON INDIVIDUALS AND THEIR LIFESTYLES}

\begin{tabular}{|c|c|}
\hline № и название фрактора & $\begin{array}{c}\text { Изменения В жизни под влиянием Интернета, } \\
\text { отмечаемье респондентами }\end{array}$ \\
\hline $\begin{array}{c}\text { 1-й фактор } \\
\text { «Негативное влияние: } \\
\text { торможение развития» }\end{array}$ & $\begin{array}{l}\text { Негативная оценка воздействия Интернета в целом }(0,58) . \\
\text { Перестали читать }(0,70) . \\
\text { Появилось ощущение деградации }(0,70) \text {. } \\
\text { Перестали посещать театры, кино и т. А. }(0,65) . \\
\text { Ухудшились коммуникативные навыки }(0,61) \text {. } \\
\text { Сформировались заблуждения и ошибочные мнения }(0,60) \text {. } \\
\text { Потерялись контакты с определенными людьми }(0,60)\end{array}$ \\
\hline $\begin{array}{c}\text { 2-й фактор } \\
\text { «Позитивное влияние: } \\
\text { коммуникативная сфера» }\end{array}$ & $\begin{array}{l}\text { Позитивная оценка воздействия Интернета в целом }(0,56) . \\
\text { Увеличилось число людей, с которыми осуществляется взаимо- } \\
\text { действие }(0,69) . \\
\text { Нет потери контактов с определенными людьми }(-0,56) . \\
\text { Улучшилась самооценка }(0,46) . \\
\text { Стало проще общаться }(0,42) . \\
\text { Стало больше открытости }(0,42)\end{array}$ \\
\hline $\begin{array}{c}\text { 3-й фактор } \\
\text { «Отрицание негативного } \\
\text { влияния: разносторонняя } \\
\text { активность» }\end{array}$ & $\begin{array}{l}\text { Отсутствие негативной оценки воздействия Интернета } \\
\text { в целом }(-0,45) . \\
\text { Возросла возможность развлечений в целом }(0,72) . \\
\text { Стало больше информации о событиях в мире }(0,57) \text {. } \\
\text { Стала легче доступность сведений о других }(0,43) . \\
\text { Возросла интенсивность общения }(0,40) . \\
\text { Увеличилась әрудированность }(0,37) . \\
\text { Больше стали смотреть фильмов, слушать музыки }(0,37)\end{array}$ \\
\hline
\end{tabular}


Факторный анализ делает очевидным то, что, по мнению пользователей, отрицательное влияние Интернета прежде всего затрагивает сферу гармоничного развития личности в реальном мире ее жизнедеятельности, а положительное - коммуникативную. Что же касается тех, кто отрицает негативное влияние Интернета, но не отмечает позитивного, то их вовлеченность самая разносторонняя, затрагивающая и познавательную, и коммуникативную, и развлекательную сферы.

В продолжение изучения вопроса о воздействии Интернета на личность мы решили оценить взаимосвязь включенности человека именно в социальную сеть с его собственным мнением о влиянии данных ресурсов на его жизнь, поскольку социальные сети наиболее соответствуют реализации коммуникативных потребностей личности и возможности появления принципиально новой аддикции, связанной с потребностями самореализации и публичности личности.

Одна из самых интересных выявленных закономерностей заключается в том, что чем чаще личность указывает на положительное влияние Сети, тем сильнее она ощущает и ее негативное воздействие $(\mathrm{r}=0,39$, при $\mathrm{p} \leq 0,05)$. Таким образом, наблюдается полная, казалось бы, амбивалентность чувств, вызываемых взаимодействием с Сетью. Можем предположить две взаимоисключающих гипотезы: 1) эти люди обладают высокой самокритичностью и самоконтролем с ориентацией на логические заключения; 2) они увлекаемы своими чувственными стремлениями, но отягощены сложившимися стереотипами, связанными с влиянием интернет-среды на человека, не проводя различий между ощущениями и размышлениями.

Аля продвижения в этом направлении остановимся на анализе каждого полюса оценки влияния Сети.

Если дается положительная оценка воздействия Сети, то наблюдаются следующие показатели включенности в сеть «ВКонтакте»: большое количество виртуальных друзей $(r=0,37$ при $\mathrm{p} \leq 0,05)$; частая смена «аватарок» $(\mathrm{r}=0,59$ при $\mathrm{p} \leq 0,01)$ и готовность платить реальные деньги за особые возможности сети $(\mathrm{r}=0,56$ при $\mathrm{p} \leq 0,01)$. Такие респонденты указывают и на то, что вообще предпочитают общаться именно через социальную сеть $(\mathrm{r}=0,66$ при $\mathrm{p} \leq 0,01)$. В целом мы получаем явно высокую общую вовлеченность в виртуальность. Видимо, можно предполагать, что если человек считает, что социальная сеть позитивно влияет на его жизнь, это можно рассматривать первым признаком опасного погружения в виртуальный мир.

Аостаточно любопытно, что те, кто ощущает негативное влияние сетей, также готовы платить реальные деньги за преимущества в сетях $(r=0,55$ при $\mathrm{p} \leq 0,01)$ и столь же часто меняют аватары $(\mathrm{r}=0,55$, при $\mathrm{p} \leq 0,01)$. Но есть существенное различие: в реальной жизни у них больше друзей $(r=0,45$ при $\mathrm{p} \leq 0,05)$. Это значит, что критичное восприятие Сети более благоприятно в сравнении с позитивным при условии искренности ответов.

\section{ЗАКАЮЧЕНИЕ}

Наши исследования влияния социальных сетей согласуются и с нашей оценкой влияния Интернета в целом. Полностью позитивное отношение может привести к уходу личности в виртуальный мир, постепенно вытесняя мир реальной жизнедеятельности. Основным фактором, противостоящим этому процессу, становится критичное для каждого количество реальных и удовлетворяющих человека моментов взаимодействия в реальной жизни. Блокировка данной потребности заставляет его погружаться в мир Интернета и стремиться создать такое сообщество, которое соответствует ду- 
ховному миру пользователя. Вероятно, это определяется отсутствием представлений о каких-либо перспективах собственного «Я» в реальном мире.

Негативная оценки также связана с переживанием неудовлетворенности и собственного неблагополучия. Но при этом остается сравнительный момент, основанный на критериях, усвоенных личностью в реальном мире. Интернет становится не замещением, как в первом случае, а компенсацией дефицита реальных ресурсов, подобием успокаивающих средств, которые вполне могут быть исключены при изменении жизненного контекста личности. А главное, что для этого сохраняется определенный внутриличностный потенциал.

Объективно-критичное отношение к Интернету позволяет взглянуть на него как на средство расширения возможностей и повышение эффективности жизнедеятельности человека в мире реальности, в современном интенсивном информационном потоке и гиперпространствах, которые он может включить в сферу своего сознания.

В своих прежних публикациях мы выдвигали предположение о существовании не затрагиваемой психологией, но ведущей потребности человека самому осознавать себя индивидуальным коллективным субъектом, о полном слиянии себя с ним (Козлова, Сушков, 2013: Электронный ресурс). Если реальность позволяет переживать приближение к этому, то Интернет остается очередным достижением человеческого прогресса, вспомогательным средством, облегчающим объективную социальную жизнь личности.

В случае отсутствия такого переживания Интернет как возможный запасной путь приветствуется личностью в виде среды, дающей шанс реализации такой потребности. Подвластность полному самоконтролю и творческим возможностям делает его подобным ящику Скиннера или рычагу, подающему возбуждение на центры удовольствия. Пользователь доходит до того, что не отходит от этого рычага, нажимая на клавиши компьютера снова и снова.

В случае не замещения, а лишь компенсации реальность все же доминирует в сознании пользователя. У него возникает чувство неудовлетворенности ею, но она продолжает занимать доминирующее положение. За счет Интернета он пытается дополнить свой дефицит реальных ресурсов, все же понимая суррогатность своих попыток, сохраняя при этом потенциал адекватного решения собственных проблем.

Объективно-критичная оценка Интернета возможна только при нормальной социализации личности, ее гармоничной включенности в реальность и способности эффективно использовать интернет-ресурсы. Но это зависит не от наличия интернетвозможностей, а от системы взаимоотношений человека в сообществе, с которым личность идентифицирована, и от специфики социально-психологического склада пользователя Интернета.

\section{ПРИМЕЧАНИЕ}

1 Пугностическая направленность характеризуется потребностью в преодолении опасности.

\section{СПИСОК АИТЕРАТУРЫ}

Арестова, О. Н., Бабанин, А. Н., Войскунский, А. Е. (1996) Коммуникации в компьютерных сетях: психологические детерминанты и последствия // Вестник Московского университета. Сер. 14. Психология. № 4. С. 14-20.

Арестова, О. Н., Бабанин, А. Н., Войскунский, А. Е. (1999) Исследование мотивации пользователей Интернета // Интернет и современное общество : тезисы 2-й Всерос. науч.-метод. 
конф. Санкт-Петербург, 29 ноября - 3 декабря 1999 г. СПб. : Изд-во С.-Петерб. ун-та. 196 с. C. $48-49$.

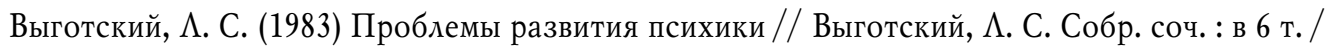
под ред. А. М. Матюшкина. М. : Педагогика. Т. 3. Проблемы развития психики. 368 с.

Граничина, О. А. (2012) Математико-статистические методы психолого-педагогических исследований. СПб. : ИзА-во ВВМ. 115 с.

Аодонов, И. Б. (2002) Тест-анкета «Эмоциональная направленность»// Аиагностика эмоционально-нравственного развития / под ред. И. Б. Аерманова. СПб. : Речь. 176 с. С. 132-134.

Ильин, Е. П. (2002) Мотивация и мотивы. СПб. : Питер. 512 с.

Ильин, Е. П. (2009) Психология общения и межличностных отношений. СПб. : Питер. 573 с.

Козлова, Н. С. (2014а) Социальная сеть «Инстаграм» как социально-психологическое явление // Молодой ученый. № 16. С. 387-390.

Козлова, Н. С. (2014b) Социальные сети: теоретический анализ и эмпирическое исследование // Гуманитарные проблемы современности: человек и общество / С. В. Голикова, О. М. Горева, И. В. Гурьянова и др. Новосибирск : Изд-во ЦРНС. Кн. 22. 248 с. С. 162-181.

Козлова, Н. С., Сушков, И. Р. (2013) Стремление к публичности и самопрезентации как проявление специфических потребностей, реализуемых личностью в интернет-среде [Электронный ресурс] // Информационный гуманитарный портал «Знание. Понимание. Умение». № 6 (ноябрь - декабрь). URL: http://www.zpu-journal.ru/e-zpu/2013/6/Kozlova_Sushkov_PublicitySelf-Presentation (дата обращения: 17.09.2014).

Козлова, Н. С., Сушков, И. Р. (2014) Факторы, лежащие в основе вовлеченности личности в интернет-пространство // Триединство здоровья нации, качества жизни и гармоничного общества как основа устойчивого развития России в XXI веке : материалы междунар. конгресса : в 2 т. / отв. ред., сост. А. А. Журавлев, Н. П. Фетискин, Т. И. Миронова. М. ; Кострома : АСППАМ. Т. 1.506 с. С. 84-93.

Мясищев, В. Н. (2003) Психология отношений. М. ; Воронеж : ИзА-во Моск. психол.-соц. ин-та ; ИзА-во НПО «МОАЭК». 356 с.

Рогов, Е. И. (1999) Настольная книга практического психолога. М. : Гуманит. изд. центр «ладос». 480 с.

Романов, И. В. (2005) Влияние интернет-среды на индивидуально-психологические качества пользователей научно-информационных сайтов : дис. ... канд. психол. наук. Иваново. 199 с.

Румянцева, Т. В. (2006) Тест Куна. Тест «Кто Я?»// Румянцева, Т. В. Психологическое консультирование: диагностика отношений в паре. СПб. : Речь. 176 с. С. 82-103.

Сушков, И. Р. (2008) Психологические отношения человека в социальной системе. М. : Иза-во Института психологии РАН. 412 с.

Сушков, И. Р. (1999) Психология взаимоотношений. М. : Академический проект ; Изд-во Института психологии РАН. 448 с.

Сушков, И. Р., Козлова, Н. С. (2014) Взаимосвязь базовых процессов и потребностей, реализуемых личностью в интернет-среде // Вестник Костром. гос. ун-та им. Н. А. Некрасова. Сер. Педагогика. Психология. Социальная работа. Ювенология. Социокинетика. Т. 20. № 3. C. 58-62.

Фриндте, В., Келер, Т. (2000) Публичное конструирование «Я»в опосредствованном компьютером общении. Гуманитарные исследования в Интернете / под ред. А. Е. Войскунского. М. : Можайск-Терра. 431 с. С. 40-54.

Чудова, Н. В., Евлампиева, М. А., Рахимова, Н. А. (2001) Психологические особенности коммуникативного пространства Интернета [Электронный ресурс] // Проблемы медиапсихологии : материалы секции «Медиапсихология» Междунар. науч.-практ. конф. «Журналистика в 2000 году: реалии и прогнозы развития». М. : МГУ, 2001. URL: http://evartist.narod.ru/text7/ 47.htm (дата обращения: 13.07.2015).

Фетискин, Н. П., Козлов, В. В., Мануйлов, Г. М. (2002) Социально-психологическая диагностика развития личности и малых групп. М. : Изд-во Ин-та психотерапии. 490 с. 
Facebook profiles reflect actual personality not self-idealization (2010) / M. D. Back, J. M. Stopfer, S. Vazire, S. Gaddis, S. C. Schmukle, B. Egloff, S. D. Gosling // Psychological Science. № 21. P. 372-374.

Internet paradox: A social technology that reduces social involvement and psychological wellbeing? (1998) / R. Kraut, V. Lundmark, M. Patterson, S. Kiesler, T. Mukopadhyay, W. Scherlis // American Psychologist. Vol. 53 (9). P. 1017-1031.

Manifestations of personality in online social networks: self-reported Facebook-related behaviors and observable profile information (2011) / S. D. Gosling, A. A. Augustine, S. Vazire, N. Holtzman, S. Gaddis // Cyberpsychology, Behavior and Social Networking. № 14 (9). P. 483-488.

Joinson, A. (2003) Understanding the psychology of Internet behaviour: Virtual worlds, real lives. Houndmills, UK ; N. Y. : Palgrave Macmillan. 224 p.

Turkle, Sh. (1995) Life on the screen: Identity in the age of the Internet. N. Y.: A Touchstone Book. $354 \mathrm{p}$.

Аата поступления: 23.04.2015 2.

\section{THE INTERNET'S IMPACT ON INDIVIDUALS AND THEIR LIFESTYLES \\ N. S. KOZLOVA \\ (IVANOVO STATE UNIVERSITY)}

In this article we assess the influence, both positive and negative, of the Internet on individuals. Currently, there is a trend towards a whole new multi-aspect field of psychological science devoted to studying the aspects of human behavior mediated by the Internet. Thus studying the strength, polarity, and specifics of the virtual world's influence over its users, whose number grows continuously and includes a significant number of children and adolescents, has become very important and demands further empiric research.

In this study, the emphasis is made on the assessment of the overall effect caused by the Internet, and also on the consequences of the person's involvement in social networks. The study conducted by the author in 2013-2014 included 153 Internet-users aged 18-72 from the cities of Moscow, St. Petersburg, Yaroslavl, Ivanovo and Ivanovo oblast. The data were analyzed with the help of the methods of descriptive statistics, correlation and factor analysis.

People using the Internet in a productive way, whose Internet activity is typically low, generally remain unaffected. On the other hand, those who report strong positive or negative effects of using the Internet tend to be deeply involved. Rather than using the technical means constructively, they tend to have an increased desire for communication, by means of which they achieve virtual self-presentation and satisfy their desire for publicity.

The users who have their personality traits or lifestyle changed due to their usage of the Internet risk developing the Internet addiction. When studying the socio-psychological features of such users, we learn that they tend to have problems in the areas of real social identity and subjective well-being. They are also characterized by the diversity and strength of their emotions. Studying the influence of the social networks, we have discovered similar tendencies. We can also conclude that the individual's social environment defines the disposition to and involvement in the virtual world and thus its influence.

Keywords: Internet-space, social networks, internet-influence, internet-addiction, communication, self-presentation, publicity, social identity.

\section{REFERENCES}

Arestova, O. N., Babanin, L. N. and Voiskunskii, A. E. (1996) Kommunikatsii v komp'iuternykh setiakh: psikhologicheskie determinanty i posledstviia [Communication in computer networks: psychological determinants and consequences]. Vestnik Moskovskogo universiteta, ser. 14, Psikbologiia, no. 4, pp. 14-20. (In Russ.).

Arestova, O. N., Babanin, L. N. and Voiskunskii, A. E. (1999) Issledovanie motivatsii pol'zovatelei Interneta [A study of the motivation of the Internet users]. In: Internet $i$ sovremennoe obshchestvo. 
Tezisy 2-i Vserossiiskoi nauchno-metodicheskoi konferentsii [Internet and contemporary society. Proceedings of the 2nd All-Russia research and practical conference]. St. Petersburg, St. Petersburg University Press, 196 p. Pp. 48-49. (In Russ.).

Vygotskii, L. S. (1983) Problemy razvitiia psikhiki [Problems of development of the psyche]. In: Vygotskii L. S. Sobranie sochinenii [Collected works]: in 6 vols./ ed. by A. M. Matiushkina. Moscow, Pedagogika Publ. Vol. 3. Problemy razvitiia psikhiki [Problems of development of the psyche]. $368 \mathrm{p}$. (In Russ.).

Granichina, O. A. (2012) Matematiko-statisticheskie metody psikbologo-pedagogicheskikb issledovanii [Mathematical and statistical methods of psychological and educational research]. St. Petersburg, VVM Publ. 115 p. (In Russ.).

Dodonov, I. B. (2002) Test-anketa «Emotsional'naia napravlennost'» [Test questionnaire «Emotional orientation»]. In: Diagnostika emotsional'no-nravstvennogo razvitiia [Diagnosis of emotional-moral development]/ ed. by I. B. Dermanov. St. Petersburg, Rech' Publ. 176 p. Pp. 132-134. (In Russ.).

Il'in, E. P. (2002) Motivatsiia i motivy [Motivation and motives]. St. Petersburg, Piter Publ. 512 p. (In Russ.).

Il'in, E. P. (2009) Psikbologiia obshcheniia i mezhlichnostnykb otnoshenii [Psychology of communication and interpersonal relations]. St. Petersburg, Piter Publ. 573 p. (In Russ.).

Kozlova, N. S. (2014a) Sotsial'naia set' «Instagram» kak sotsial'no-psikhologicheskoe iavlenie [Instagram as a socio-psychological phenomenon]. Molodoi uchenyi, no. 16, pp. 387-390. (In Russ.).

Kozlova, N. S. (2014b) Sotsial'nye seti: teoreticheskii analiz i empiricheskoe issledovanie [Social networks: theoretical analysis and empirical research]. In: Gumanitarnye problemy sovremennosti: chelovek $i$ obshchestvo [Humanitarian issues of contemporary times: man and society]/ S. V. Golikova, O. M. Goreva, I. V. Gur'ianova et al. Novosibirsk, TsRNS Publ. Vol. 22. 248 p. Pp. 162-181. (In Russ.).

Kozlova, N. S. and Sushkov, I. R. (2013) Stremlenie k publichnosti i samoprezentatsii kak proiavlenie spetsificheskikh potrebnostei, realizuemykh lichnost'iu v internet-srede [The aspiration for publicity and self-presentation as a manifestation of the specific needs achieved in the Internet as a medium]. Informatsionnyi gumanitarnyi portal «Znanie. Ponimanie. Umenie», no. 6 (November December) [online] Available at: http:.www.zpu-journal.ru/e-zpu/2013/6/Kozlova_Sushkov_Publicity-Self-Presentation (accessed 17.09.2014). (In Russ.).

Kozlova, N. S. and Sushkov, I. R. (2014) Faktory, lezhashchie v osnove vovlechennosti lichnosti $\mathrm{v}$ internet-prostranstvo [The factors underlying the involvement of the individual in the Internet space]. In: Triedinstvo zdorov' ia natsii, kachestva zhizni i garmonichnogo obshchestva kak osnova ustoichivogo razvitiia Rossii $v$ XXI veke. Materialy mezhdunarodnogo kongressa [The tri-unity of the health of the nation, quality of living and harmonious society as a basis for Russia's sustainable development in $21^{\text {st }}$ century: Proceedings of an international congress]: in 2 vols. / ed. by A. L. Zhuravlev, N. P. Fetiskin and T. I. Mironova. Moscow, Kostroma, Institute of Psychology of Russian Academy of Sciences Publ. Vol. 1. 506 p. Pp. 84-93. (In Russ.).

Miasishchev, V. N. (2003) Psikbologiia otnoshenii [The psychology of relationships]. Moscow, Voronezh, Moscow Institute for Psychology and Social Science, NPO «MODEK». 356 p. (In Russ.).

Rogov, E. I. (1999) Nastol' naia kniga prakticheskogo psikbologa [Handbook of a practicing psychologist]. Moscow, VLADOS Publ. 480 p. (In Russ.).

Romanov, I. V. (2005) Vliianie internet-sredy na individual' no-psikbologicheskie kachestva pol'zovatelei nauchno-informatsionnykb saitov [The influence of the Internet environment on the individual psychological qualities of users of science sites]. Dis. Cand. of Psychology. Ivanovo. 199 p. (In Russ.).

Rumiantseva, T. V. (2006) Test Kuna. Test «Kto Ia?» [Kuhn's test. Test "Who am I?"]. In: Rumiantseva T. V. Psikhologicheskoe konsul'tirovanie: diagnostika otnoshenii v pare [Psychological consulting: Diagnostics of a couple's relations]. St. Petersburg, Rech' Publ. 176 p. Pp. 82-103. (In Russ.). 
Sushkov, I. R. (2008) Psikbologicheskie otnosheniia cheloveka $v$ sotsial' noi sisteme [An individual's psychological relations within the social system]. Moscow, Institute of Psychology of Russian Academy of Sciences Publ. 412 p. (In Russ.).

Sushkov, I. R. (1999) Psikbologiia vzaimootnoshenii [Psychology of mutual relationships]. Moscow, Akademicheskii proekt; Institute of Psychology, Russian Academy of Sciences, 448 p. (In Russ.).

Sushkov, I. R. and Kozlova, N. S. (2014) Vzaimosviaz' bazovykh protsessov i potrebnostei, realizuemykh lichnost'iu v internet-srede [The interrelation between basic processes and needs achieved by an individual in the Internet environment]. Vestnik Kostromskogo gosudarstvennogo universiteta im. N. A. Nekrasova. Ser. Pedagogika. Psikbologiia. Sotsial'naia rabota. Iuvenologiia. Sotsiokinetika, vol. 20, no. 3, pp. 58-62. (In Russ.).

Frindte, V. and Keler, T. (2000) Publichnoe konstruirovanie «Ia» v oposredstvovannom komp'iuterom obshchenii [The public construction of the «I» in computer-mediated communication]. In: Gumanitarnye issledovaniia $v$ Internete [Humanitarian studies on the Internet] / ed. by A. E. Voiskunski. Moscow, Mozhaisk-Terra Publ. 431 p. Pp. 40-54. (In Russ.).

Chudova, N. V., Evlampieva, M. A. and Rakhimova, N. A. (2001) Psikhologicheskie osobennosti kommunikativnogo prostranstva Interneta [Psychological peculiarities of the communicative space of the Internet]. In: Problemy mediapsikhologii: materialy sektsii «Mediapsikhologiia» Mezhdunar. nauch.-prakt. konf. «Zhurnalistika v 2000 godu: realii i prognozy razvitiia». Moscow. Moscow State University. [on-line] Available at: http: evartist.narod.ru/text7/47.htm (accesses 13.07.2015). (In Russ.).

Fetiskin, N. P., Kozlov, V. V. and Manuilov, G. M. (2002) Sotsial'no-psikbologicheskaia diagnostika razvitiia lichnosti $i$ malykh grupp [Socio-psychological diagnosis of the development of individuals and small groups]. Moscow, Institute of Psychotherapy. 490 p. (In Russ.).

Facebook profiles reflect actual personality not self-idealization (2010) / Back, M. D., Stopfer, J. M., Vazire, S., Gaddis, S., Schmukle, S. C., Egloff, B. and Gosling, S. D. Psychological Science, no. 21, pp. 372-374.

Manifestations of personality in online social networks: self-reported Facebook-related behaviors and observable profile information (2011) / Gosling, S. D., Augustine, A. A., Vazire, S., Holtzman, N. and Gaddis, S. Cyberpsychology, Bebavior and Social Networking, no. 14 (9), pp. 483-488.

Joinson, A. (2003) Understanding the psychology of Internet behaviour: Virtual worlds, real lives. Houndmills, United Kingdom, New York, Palgrave Macmillan Publ. 224 p.

Internet paradox: A social technology that reduces social involvement and psychological wellbeing? (1998) / Kraut, R., Lundmark, V., Patterson, M., Kiesler, S., Mukopadhyay, T. and Scherlis, W. American Psychologist, vol. 53 (9), pp. 1017-1031.

Turkle, Sh. (1995) Life on the screen: Identity in the age of the Internet. New York, A Touchstone Book Publ. 354 p.

Submission date: 23.04.2015.

Козлова Наталия Сергеевна - кандидат психологических наук, доцент кафедры социальной психологии. Ивановский государственный университет. Адрес: 153025, Россия, г. Иваново, ул. Ермака, д. 39. Тел.: +7 (4932) 32-74-52. Эл. адреc: nat-tycuk@yandex.ru

Kozlova Natalia Sergeevna, Candidate of Psychology, Associate professor, Department of social psychology, Ivanovo State University. Postal address: 39 Ermaka St., 153025 Ivanovo, Russian Federation. Tel.: +7 (960) 509-31-41. E-mail: nat-tycuk@yandex.ru 